SECTION 11. Biology. Ecology. Veterinary.

Leonid Alexandrovich Chunihin

Ph.D. in Biological Sciences, Associate Professor, Gomel State Medical University, Republic of Belarus

Artur Leonidovich Chehovskii Graduate student,

Gomel State University named Skaryna, Republic of Belarus chehovskii@mail.ru

Denis Nikolaevich Drozdov Ph.D. in Biological Sciences, Associate Professor, Gomel State University named Skaryna, Republic of Belarus

\title{
ANALYSIS OF FACTORS AS OF RADON INDEX EXAMPLE OF VITEBSK REGION
}

Abstract: The article addresses the issue of natural radioactive gas - radon. It is shown that increasing the number of factors that determine the presence of radon in the soil, increases the coefficient of correlation of the proposed measure radon and radon activity concentration in the buildings of the rural settlements of the Vitebsk region. The resulting radon indicator can be used to map the territory for radon risk in a large-scale version.

Keywords: radon, radon index, Vitebsk region, mapping the territory.

\section{АНАЛИЗ ФАКТОРОВ РАДОНОВОГО ПОКАЗАТЕЛЯ НА ПРИМЕРЕ ВИТЕБСКОЙ ОБЛАСТИ}

\begin{abstract}
Аннотация: $\quad$ В статье затрагивается проблема естественного радиоактивного газа - радона. Показано, что при увеличении числа факторов, определяюших наличие радона в почве, повышается коэффициент коррелячионной связи предложенного радонового показателя и объемной активности радона в помещениях зданий сельских населенных пунктов Витебской области. Полученный радоновый показатель может использоваться для картирования территории по радоновому риску в крупномасштабном варианте.
\end{abstract}

Ключевые слова: радон, радоновый показатель, Витебская область, картирование территории.

Введение. Радон - радиоактивный газ, образующийся в процессе радиоактивного распада в цепочке естественных радионуклидов семейств урана и тория. Согласно оценке НКДАР ООН, радон и его дочерние продукты определяют примерно 3/4 годовой индивидуальной эффективной дозы облучения, получаемой населением от земных источников радиации [1]. Радон, являясь компонентом воздуха, попадает в легкие человека при дыхании. Воздействие $\alpha$-излучения на высокочувствительные клетки дыхательной системы - одна из причин возникновения рака. По оценкам экспертов МКРЗ облучение населения за счет радона обуславливает до $20 \%$ общего количества заболеваний раком легких [2]. Естественный изотоп радона ${ }^{222} \mathrm{Rn}$, являясь наиболее долгоживущим (период полураспада 3,82 дня), вместе с его дочерними продуктами распада (ДПР) вносят наиболее существенный вклад в облучение человека. 
Принципиально новые подходы к оценке радоновой опасности и радиационной защите от радона и его ДПР были показаны в Публикации № 65 МКР3, 1993 г. [3]. Одним из основных тезисов данной публикации является необходимость введение понятия и критериев для оценки радоноопасных зон, что является очень важным в случаях недостатка ресурсов для проведения полномасштабных исследований, как, например, в Беларуси. Известно, что основным источником поступления радона в воздух помещений является почва [4]. Учитывая это, можно провести картирование территории по радоновой опасности с использованием геологических показателей, определяющих концентрации радона, выделить наиболее радоноопасные зоны и предложить необходимые противорадоновые мероприятия.

Целью настоящей работы являлся анализ изменения корреляционной связи при увеличении количества показателей, определяющих наличие радона в почвах и породах, сочетание которых выступает в качестве радонового показателя, указывающего на степень радоноопасности территории.

Материалы и методы исследований. Материалами для данной работы являлись результаты измерения объемной активности (OA) радона в типичных помещениях сельских населенных пунктов 15 районов Витебской области. Эти данные были получены при широкомасштабных обследованиях, выполненных специалистами НИИ морской и промышленной медицины (г. Санкт-Петербург) [5]. Измерения проводились в помещениях сельских одноэтажных зданий, в которых можно ожидать максимальные уровни ОА радона, поступающего в основном из почвы.

В исследованиях использовался ряд карт: дочернобыльские карты мощности экспозиционной дозы (МЭД) на территории Беларуси в период 1969-1985 [6]; геологические карты Беларуси, на которых показано расположение пород и почв с различным содержанием урана [6]; данные по проницаемости различных пород для радона [7]; гидрогеологические карты территории Беларуси с глубинами залегания первого от поверхности водоносного горизонта [8].

Результаты исследований и их обсуждение. Следует отметить, что ОА радона в помещениях жилых зданий является весьма вариабельной величиной и во многом зависит от конструктивных особенностей и защитных свойств зданий. Если принять, что в сельских населенных пунктах преобладают одноэтажные деревянные строения с простыми фундаментами и деревянными полами, то можно считать, что поступление радона в помещение определяется, в основном, свойствами подстилающих пород. Исходя из этого, можно предложить в качестве радонового показателя величину, равную произведению показателей, обуславливающих наличия радона в почвах и породах, в относительных единицах: мощность дозы дочернобыльского фона, запас урана в почвах, проницаемость почв и пород для радона, и глубину залегания первого водоносного горизонта. При добавлении каждого из перечисленных показателей к предыдущим ожидается увеличение коэффициента корреляции между радоновым показателем и ОА радона.

По материалам измерений ОА радона, проведенных в Витебской области, были определены среднерайонные значения ОА радона.

Первым важным показателем, который связан с ОА радона является МЭД. Учитывая, что гамма-фон на местности определяется, в основном, радионуклидами 3-х естественных радиоактивных рядов уранов и тория, а также калия-40 (мощность дозы от которого принята постоянной) - колебания МЭД определяется концентрацией естественных радионуклидов в почвах. Таким образом, МЭД может опосредованно указывать на наличие радона.

Для того чтобы исключить влияние искусственных радионуклидов, выпавших на территории Беларуси после аварии на Чернобыльской АЭС в исследованиях использовались дочернобыльские карты МЭД, значения которых были нормированы на 
максимальную величину - 12 мкР/час, принятую за 1. По картам были определены средневзвешенные значения относительного показателя МЭД для исследуемых районов Витебской областей, после чего был проведен корреляционный анализ данных для определения степени и характера связи получившихся значений МЭД и ОА радона в помещениях сельских зданий.

Коэффициент линейной корреляции, указывающий на связь средневзвешенных значений относительного показателя МЭД для исследуемых районов Витебской области и среднерайонных значений ОА радона, составил $r=0,48$. Имеет место средняя по силе, прямая связь показателя МЭД и ОА радона. Эмпирическое значение $\mathrm{t}$-критерия не превышает статистическое значение при уровне значимости $\mathrm{p}>0,05-$ корреляция является не достоверной. Таким образом, показано, что при использовании только одного показателя можно давать лишь приблизительную оценку ОА радона в помещениях зданий.

Следующим показателем, определяющим ОА радона, является запас урана в почвах и породах. Принимая во внимание, что уран является материнской породой для образования радона - концентрации урана в почвах будут определять содержание радона и как следствие его ОА.

Было выделено 9 геологических пород, существующих на территории Беларуси, различающиеся по уровню содержания урана [9]. Эти данные были нормированы на значение максимального содержания урана в породе (глина), принятое за 1 и определены средневзвешенные значения относительного показателя запаса урана в почвах для каждого из районов. Полученный массив данных был добавлен в качестве сомножителя к значениям относительного показателя МЭД, и проведен корреляционный анализ данных для определения степени и характера связи получившихся значений радонового показателя (состоящего из средневзвешенных значений относительных показателей МЭД и запаса урана в почвах) и ОА радона в помещениях сельских зданий.

Коэффициент линейной корреляции полученного радонового показателя и среднерайонных значений ОА радона, составил $r=0,54$. Имеет место средняя по силе, прямая связь данного показателя и ОА радона для районов Витебской области. Эмпирическое значение t-критерия превышает статистическое значение при уровне значимости $\mathrm{p}<0,05$ - корреляция является достоверной.

Необходимо также учитывать, что эксхаляция радона зависит от проницаемости почвы, которая в свою очередь в большей степени зависит от коэффициента фильтрации радона в грунтах [10]. Исходя из того факта, что период полураспада радона ${ }^{222} \mathrm{Rn}$ составляет около 3,8 суток, скорость его прохождения через слой почвы (которая определяется коэффициентом фильтрации) имеет важное значение, и обуславливает конечную ОА радона в помещениях зданий.

Значения коэффициента фильтрации были нормированы на максимальную величину (песчано-гравийная смесь), принятую за 1. Определены средневзвешенные значения относительного показателя коэффициента фильтрации радона в почве для каждого из районов. Значения показателя коэффициента фильтрации были добавлены в качестве сомножителя к полученному произведению средневзвешенных относительных показателей МЭД и запаса урана в почвах. После этого проведен корреляционный анализ для определения степени и характера связи получившихся значений радонового показателя (состоящего из средневзвешенных значений относительных показателей МЭД, запаса урана в почвах, коэффициента фильтрации) и ОА радона в помещениях сельских зданий.

Коэффициент линейной корреляции, указывающий на связь значений полученного радонового показателя и среднерайонных значений ОА радона, составил 
$\mathrm{r}=0,66$. Имеет место средняя по силе, прямая связь данного показателя и ОА радона для исследуемых районов Витебской области. Эмпирическое значение t-критерия превышает статистическое значение при уровне значимости $\mathrm{p}<0,05-$ корреляция является достоверной.

Также, важным фактором, определяющим концентрации радона, является уровень залегания первого от поверхности водоносного горизонта. При уровне в 1-2 м от поверхности - почвенный радон почти полностью поглощается, а при уровне более 10 м - весь выделенный радон остается в почвенном воздухе [11].

Значения глубины залегания первого водоносного горизонта были нормированы на максимальную величину $(10$ м), принятую за 1 . После определены средневзвешенные значения относительного показателя уровня залегания первого водоносного горизонта для каждого из районов. Значения показателя уровня залегания первого водоносного горизонта были добавлены в качестве сомножителя к полученному произведению средневзвешенных относительных показателей МЭД, запаса урана в почвах, коэффициента фильтрации. После этого проведен корреляционный анализ для определения степени и характера связи получившихся значений радонового показателя (состоящего из средневзвешенных значений относительных показателей МЭД, запаса урана в почвах, коэффициента фильтрации, уровня залегания первого водоносного горизонта) и ОА радона в помещениях сельских зданий. Итоговый график данной корреляционной связи, образованной четырьмя компонентами радонового показателя, представлен на (рис. 1).



\section{Рисунок 1 - Зависимость среднерайонных значений ОА радона в помещениях от} радонового показателя $(\mathbf{M} \cdot \mathbf{U} \cdot \mathbf{F} \cdot \mathbf{W})$.

Коэффициент линейной корреляции, указывающий на связь значений полученного радонового показателя для исследуемых районов Витебской области и среднерайонных значений ОА радона, составил $r=0,73$. Имеет место сильная, прямая связь данного показателя и ОА радона. Эмпирическое значение t-критерия превышает статистическое значение при уровне значимости $\mathrm{p}<0,05$ - корреляция является достоверной. 
Заключение. Предложенный радоновый показатель имеет достаточно сильную и достоверную связь со значениями ОА радона в помещениях зданий. Данный показатель учитывает целый ряд факторов и приведенные корреляционные зависимости показывают, что увеличение числа показателей, определяющих наличие радона в почвах и породах, значительно повышает коэффициент корреляции радонового показателя и способствует более точной оценке ОА радона. Такой показатель служит основой для определения радоноопасности территории. С его помощью можно определить географическое положение критических зон радоноопасности и составить тематические карты этих территорий по радоновому риску.

\section{References:}

1. Радиация. Дозы эффекты риск: пер. с англ. - М.: Мир, 1990. - 80 с.

2. Риск возникновения рака легкого при облучении радоном и продуктами его распада. Заявление по радону / под ред. М.В. Жуковского, С.М. Киселева, А.Т. Губина // Перевод публикации № 115 МКРЗ. - М.: ФГБУ ГНЦ ФМБЦ им. А.И. Бурназяна ФМБА России, 2013. - 92 с.

3. Защита от радона-222 в жилых зданиях и на рабочих местах / Публикация № 65 МКРЗ. - М.: Энергоатомиздат, 1995. - 78 с.

4. Бекман, И.Н. Радон: враг, врач и помощник / И.Н. Бекман. - М.: МГУ, 2000. - 205 c.

5. Радоновый мониторинг Могилевской и Гомельской области Республики Беларусь: отчет о НИР (закл.) / Научно-исследовательский институт промышленной и морской медицины; рук. Э.М. Крисюк. - СПб., 1992. - 205 с.

6. Karabanov, A.K. Impact of geological structures of Belarus on Radon Concentration in Air Workshop on Natural Radiation and Radon / Seminar on Radon, Stockholm, SSM, 25-27 January, 2009.

7. Беляшов, А.В. Оценка гидрогеологических параметров по данным геофизических исследований в скважинах: Методическое руководство / А.В. Беляшов [и др.]. Минск: Фонды геофизической экспедиции, 2008. - 43 с.

8. Богомолов, Г.В. Гидрогеологическая карта четвертичных отложений Белорусской ССР / Г.В. Богомолов [и др.]. - Минск, 1963.

9. McDonough, W.F. The Composition of the Earth / W.F. McDonough, S.S. Sun // Chem. Geol. - 1995. - № 1. - P. 223-253.

10. Адушкин, В.В. Поля почвенного радона в восточной части Балтийского щита / В.В. Адушкин, И.И. Дивков, С.А. Кожухов // Динамические процессы в системе внутренних и внешних взаимодействующих геосфер / В.В. Адушкин, И.И. Дивков, С.А. Кожухов. - М.: Геос, 2005. - С. 173-178.

11. Выполнение комплексной геофизической съемки на площадке возможного размещения АЭС и прогноз миграции радионуклидов с подземными водами (Шкловско-Горецкий пункт, Кукшиновская площадка): Отчет о НИР (закл.) / Бел. геофиз. экспед; рук. темы А.В. Гаврилов. - Минск, 2008. - 257 с. 